Tohoku J. exp. Med., 1977, 123, 323-327

\title{
Plasma Cortisol Concentration in Newborn Infants
}

\author{
Takeshi Yoshida, Yutaka Hattori and Kirchiro Noda \\ Department of Obstetrics and Gynecology, Kinki University \\ School of Medicine, Sayama, Osaka-fu 589
}

\begin{abstract}
Yosmida, T., Hatrori, Y. and Noda, K. Plasma Cortisol Concentration in Newborn Infants. Tohoku J. exp. Med., 1977, 123 (4), 323-327__ Plasma cortisol was measured in cord and neonatal blood. Cortisol concentration in neonates decreased rapidly during the first three days after delivery and thereafter remained at an almost constant level. The more the delivery was stressful, the higher the cortisol in the 1-day-old infant, but the concentration came down to the same level as in the less stressful delivery on the 3rd day of the infants' life. The cortisol level in vaginal delivery after spontaneous labor was not different from that in vaginal delivery after oxytocin induced labor. Cortisol in small-fordate infants or infants with hyperbilirubinemia was lower than in average-for-date infants or infants without hyperbilirubinemia. cortisol; newborn infants
\end{abstract}

The relationship between the onset of labor and the role of the fetal adrenal cortex has been considered important on the basis of experimental findings in animal (Drost and Holm 1968; Liggins 1969). There are several reports demonstrating the role of adrenocortical hormones in the maturation of the fetus and the neonate, especially in the maturation of the respiratory organs which is of essential importance in the extrauterine life (Motoyama et al. 1973; Torday et al. 1975). Also there have been many studies attempting to clarify the relationship between the onset of labor and the maturation of the fetal adrenal cortex by determination of the cortisol in cord blood at birth (Pokely 1973; Murphy 1973; Sybulski and Maughan 1976). However, it seemed difficult to draw the clear conclusion on the relationship from these studies, because the cord blood cortisol level is greatly influenced by the stress of labor (Kawahara 1958). In this study, we measured cortisol in serially drawn neonatal blood to obtain information as to when neonates are relieved from the influence of the delivery and to reveal the relationship between the stable cortisol level and the onset of labor or the condition of the neonates.

\section{Materials and Methods}

Cord blood and neonatal blood of infants born after 39 to 41 weeks' gestation, drawn by the puncture of the sole of the foot into capillaries, were centrifuged and the plasma obtained were stored frozen at $-20^{\circ} \mathrm{C}$ till the assay of cortisol. The sampling of neonatal blood was performed between 09:00 a.m. and 12:00 noon. The plasma cortisol was determined with a radioimmunoassay kit of CEA-IRE-SORIN after washing the plasma with ten volumes of petroleum ether.

Received for publication, May 21, 1977. 


\section{RESULTS}

Time course of plasma cortisol concentration following normal delivery. Cortisol levels of the serial plasma of 30 average-for-date infants born on spontaneous delivery are shown in Fig. 1. The neonatal plasma cortisol level fell rapidly during the first three days after delivery and remained almost constant thereafter.

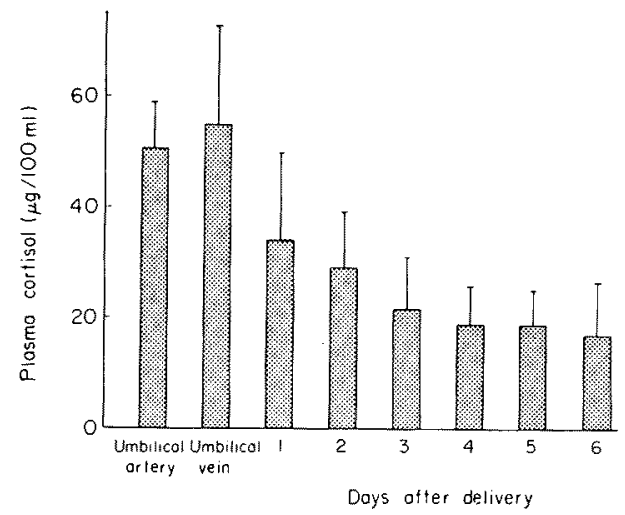

Fig. 1. Plasma cortisol concentrations of AFD infants.

Relationship between the duration of labor and the level of neonatal plasma cortisol. In Table 1 are shown the plasma cortisol concentrations at the 1st, 3rd and 5th days of three groups of infants classified according to the duration of labor from its onset to the completion of delivery. The longer the labor lasted, the higher the infant's plasma cortisol level after birth, and especially the elevation was prominent on the first day. Five days after birth, however, the neonatal cortisol levels in these three groups were not significantly different.

TABLE 1. Duration of labor and neonatal cortisol concentration

\begin{tabular}{cccc}
\hline & \multicolumn{3}{c}{$\begin{array}{c}\text { Cortisol concentrations at days after delivery } \\
\text { indicated below }(\mu \mathrm{g} / 100 \mathrm{ml})\end{array}$} \\
\cline { 2 - 4 } & 1 & 3 & 5 \\
\hline $\begin{array}{c}\text { Less than } 4 \mathrm{hr} \\
(N=14)\end{array}$ & $30.2 \pm 14.3$ & $21.1 \pm 6.0$ & $16.9 \pm 3.3$ \\
$4-8 \mathrm{hr}(N=7)$ & $34.5 \pm 16.0$ & $22.1 \pm 7.5$ & $17.2 \pm 5.6$ \\
More than $8 \mathrm{hr}$ & $53.8 \pm 8.6$ & $24.8 \pm 7.4$ & $18.0 \pm 6.1$ \\
$(N=5)$ & & & \\
\hline
\end{tabular}

Mean土s.D.

Plasma cortisol in infants born to primipara mothers and in infants to multipara mothers. The plasma cortisol concentrations of the newborn infants born to primipara mothers and those to multipara mothers are shown in Table 2. The plasma cortisol concentration in 1-day-old neonates born to primipara mothers 
was higher than the value in those born to multipara mothers. On the 3rd and 5th days, however, the values in both groups were not significantly different.

TABLE 2. Neonatal cortisol concentrations of primipara and multipara

\begin{tabular}{cccc}
\hline & \multicolumn{3}{c}{$\begin{array}{c}\text { Cortisol concentrations at days after delivery } \\
\text { indicated below }(\mu \mathrm{g} / 100 \mathrm{ml})\end{array}$} \\
\cline { 2 - 4 } & 1 & 3 & 5 \\
\hline $\begin{array}{c}\text { Primipara } \\
(N=10) \\
\begin{array}{c}\text { Multipara } \\
(N=16)\end{array}\end{array}$ & $38.8 \pm 16.2$ & $21.5 \pm 9.2$ & $18.9 \pm 8.0$ \\
\hline
\end{tabular}

Mean \pm s.D.

Plasma cortisol in infants delivered by elective Cesarean section. As shown in Table 3, the plasma cortisol levels in infants delivered by the elective Cesarean section was remarkably lower on the first day after birth as compared with the values of those born by transvaginal delivery. Subsequently, the level of plasma cortisol of the former infants became similar to those in infants born by transvaginal delivery.

TABLE 3. Neonatal cortisol concentration of infants born by elective Cesarean section

\begin{tabular}{cccc}
\hline & \multicolumn{3}{c}{$\begin{array}{c}\text { Cortisol concentrations at days after delivery } \\
\text { indicated below }(\mu \mathrm{g} / 100 \mathrm{ml})\end{array}$} \\
\cline { 2 - 4 } & 1 & 3 & 5 \\
\hline $\begin{array}{c}\text { Elective C.S. } \\
(N=4) \\
\text { Vaginal delivery } \\
(N=30)\end{array}$ & $28.6 \pm 3.4$ & $19.4 \pm 10.3$ & $20.9 \pm 10.3$ \\
\hline
\end{tabular}

Mean \pm S.D.

Comparison of plasma cortisol levels in infants born by spontaneous labor and in those by oxytocin-induced labor. The plasma cortisol levels in infants born by labor with spontaneous onset was not significantly different from the values in those by oxytocin-induced labor as can be seen in Table 4 .

TaBle 4. Neonatal cortisol levels born by spontaneous labor and oxytocin induced labor

\begin{tabular}{cccc}
\hline & \multicolumn{2}{c}{$\begin{array}{c}\text { Cortisol concentrations at days after delivery } \\
\text { indicated below }(\mu \mathrm{g} / 100 \mathrm{ml})\end{array}$} \\
\cline { 2 - 4 } & 1 & 3 & 5 \\
\hline $\begin{array}{c}\text { Spontaneous labor } \\
(N=11)\end{array}$ & $36.0 \pm 16.7$ & $21.1 \pm 7.1$ & $15.4 \pm 7.1$ \\
$\begin{array}{c}\text { Oxytocin induced } \\
\text { labor }(N=9)\end{array}$ & $35.1 \pm 15.3$ & $22.2 \pm 9.5$ & $19.4 \pm 9.2$ \\
\hline
\end{tabular}

Mean士s.D. 
Neonatal plasma cortisol in small-for-date infants and in hyperbilirubinemic infants. The plasma cortisol levels of small-for-date infants were significantly lower on the 1st, 3rd and 5th days than the values for average-for-date infants. The plasma cortisol levels of infants with elevated serum bilirubin concentration above $15 \mathrm{mg} / \mathrm{ml}$ were slightly lower than those of the normal infants on the 3rd and 5th days after delivery. Hyperbilirubinemia due to any hemolytic disease was excluded from the study.

TABLE 5. Cortisol levels of SFD and hyperbilirubinemic infants

\begin{tabular}{lccc}
\cline { 2 - 3 } & \multicolumn{2}{c}{$\begin{array}{c}\text { Cortisol concentrations at days after delivery } \\
\text { indicated below }(\mu \mathrm{g} / 100 \mathrm{ml})\end{array}$} \\
\hline SFD $(N=7)$ & 1 & 3 & 5 \\
Hyperbilirubinemic & $26.9 \pm 9.3$ & $17.1 \pm 6.0$ & $14.4 \pm 7.8$ \\
Normal $(N=6)$ & $33.2 \pm 2.1$ & $18.4 \pm 6.0$ & $16.8 \pm 9.5$ \\
\hline
\end{tabular}

Mean \pm s.D

\section{COMMENTS}

The old question in obstetrics, "what is the trigger for onset of labor" has not been clearly answered yet. The hypothesis which appears to be the most tenable is that a signal is sent when the fetus has become mature to be capable of adapting to the extrauterine environment, or that substances produced in fetus and contributing to fetal maturation pass placenta to reach a certain level in maternal site and cause the labor. There were many reports on animal experiments demonstrating that corticosteroids are involved in maturation of such a viscera as lung and that corticosteroids gave the impetus to onset of labor. Furthermore, it was reported that the women bearing an anencephalic fetus without hydramnion tended to show prolonged gestation and the prolongation was paralleled with the degree of thinness of the adrenal cortex (Anderson et al. 1969). There are many studies on the cortisol concentration in cord blood and some of them supported its relation to the onset of labor (Murphy 1973), while others did not (Pokely 1973; Sybulski and Maughan 1976). On the other hand, the cortisol concentration in cord blood was reported to be greatly influenced by stressful situation of parturition (Sybulski and Maughan 1976; Kawahara 1958). In our study, the plasma cortisol concentration in neonatal infants at 1 day age was increased with prolonged labor and with augmentation of stress at parturition and the value was lower at less stressful situation such as the elective Cesarean section. These effects of stress, however, subsided almost completely by the 3rd day of the extrauterine life and thereafter the neonatal plasma cortisol concentration would reflect the adrenocortical function of the infants. Comparison of the plasma cortisol concentrations between infants born by labor with spontaneous onset and those by oxytocin induced labor failed to reveal any significant difference. This 
result suggests that cortisol may not so intimately be related to the onset of labor, or that the adrenal cortex of fetus in the mother responding to oxytocin may have already been sufficiently matured in human being.

The cortisol concentrations of small-for-date babies and infants with hyperbilirubinemia were lower than those in normal infants. The results suggest that cortisol is involved in maturation of liver and other organs including respiratory organs.

\section{References}

1) Anderson, A.B.M., Laurence, K.M. \& Turbull, A.C. (1969) The relationship in anencephaly between the size of the adrenal cortex and the length of gestation. $J$. Obstet. Gynaec. Brit. Cwlth, 76, 196-199.

2) Drost, M. \& Holm, L.W. (1968) Prolonged gestation in ewes after foetal adrenalectomy. J. Endocr., 40, 293-296.

3) Kawahara, H. (1958) Plasma levels of 17-hydroxycorticosteroid in umbilical cord blood, with special reference to variations of the level between $\mathrm{A}$. umbilicalis and $\mathrm{V}$. umbilcalis. J. clin. Endocr., 18, 325-327.

4) Liggins, G.C. (1969) Premature delivery of foetal lambs infused with glucocorticoid. J. Endocr., 45, 515-523.

5) Motoyama, E.K., Orzalesi, M.M., Kikkawa, Y., Kaibara, M., Wu, B., Zigas, C.J. \& Cook, C.D. (1973) Effect of cortisol on the maturation of fetal rabbit lungs. Pediatrics, 48, 547-555.

6) Murphy, B.E.P. (1973) Does the human fetal adrenal play a role in parturition. Amer. J. Obstet. Gynec., 115, 521-525.

7) Pokely, T.B. (1973) The role of cortisol in human parturition. Amer. J. Obstet. Gynec., 117, 549-553.

8) Sybulski, S. \& Maughan, G.B. (1976) Cortisol levels in umbilical cord plasma in relation to labor and delivery. Amer. J. Obstet. Gynec., 125, 236-238.

9) Torday, J.S., Smith, B.T. \& Giroud, G.J.P. (1975) The rabbit fetal lung as glucocorticoid target tissue. Endocrinology, 96, 1462-1467. 